\title{
Debate e Investigación Fundamentos, fines y ámbitos de la intervención para la conservación en la Carta de Cracovia
}

Giuseppe Cristinelli

Departamento de Historia de la Arquitectura. Instituto Universitario de Arquitectura de Venecia

\section{Resumen}

Giuseppe Cristinelli interpreta minuciosamente las claves del último gran documento de la restauración, la Carta de Cracovia 2000, un texto elaborado por casi trecientos expertos internacionales procedentes de universidades europeas e instituciones como UNESCO, ICOMOS o ICCROM, para definir los principios para la conservación y restauración del patrimonio construido.

Se completa este análisis de Cristinelli, impulsor y vicepresidente de la comisión de redacción de Cracovia 2000, con la publicación del texto íntegro de la Carta en la sección Documento de esta misma revista.

\section{Palabras clave}

Carta de Cracovia

Carta de Venecia

Cartas y convenciones de patrimonio

Patrimonio cultural

Conservación

Restauración

Monumentos

Patrimonio arqueológico

Patrimonio inmueble

Patrimonio urbano
El texto de la Carta de Cracovia ofrece distintos motivos sobre los que llevar a cabo consideraciones tanto de carácter general-teórico como de naturaleza técnico-metodológica. Una exégesis completa y exhaustiva de la complejidad de los contenidos del documento sería una tarea bastante ardua, si no imposible por el momento, sobre todo para quien ha participado directamente en su redacción. En efecto, recoger en un documento de seis páginas un trabajo de cuatro años, intentando sintetizar las intervenciones de más de cuatrocientos estudiosos y especialistas ha representado un enorme esfuerzo de búsqueda de "denominadores comunes" bajo el perfil conceptual, lo cual comporta una gran riqueza de significados y de implicaciones generales, aunque ésta puede no coincidir del todo en las tesis de todos los que han participado. Cualquier lectura formulada en el código de un determinado contexto cultural resultaría, pues, poco oportuna, si no equívoca. En ese sentido, la única posibilidad es acudir a las actas de la Conferencia y a las de los congresos previos a ésta.

Como siempre sucede en estos casos, cuando se deben aunar en un único texto principios e intenciones que hacen referencia a un extenso número de países y, por consiguiente, de ámbitos culturales, incluso con connotaciones diferentes, las palabras y las frases deben asumir una denotación conceptual (extensio) lo bastante amplia como para poder acoger en su interior todas estas diferencias; y ello comporta, como consecuencia inevitable según la lógica, una disminución de la riqueza de sus connotaciones (comprehensio). En un sentido estricto, cuanto más genérico es un discurso respecto a la cantidad de temas a los que debe hacer referencia, menos rico debería ser en especificidades y precisiones analíticas. El peligro más evidente, en la relación de inversión que esta ecuación presupone, consiste en el hecho de que su posibilidad de hacerse extensible es tan alta que reduce casi a cero la de la riqueza de sus predicados. En este caso, el discurso únicamente podría revelarse como genérico hasta la banalidad por escaso y carente de contenidos.

Además, y sobre todo para evitar este inconveniente, se ha pretendido, por el momento, limitar el campo al contexto europeo, si bien queda abierto a todos aquellos paises de otros continentes que, como Estados Unidos, Canadá, México, Japón, India y otros, se identificaban en un cierto sentido con la cultura europea de la conservación o bien pretendian confrontarse con ella. Al proceder de esta manera se pudo hacer referencia a conceptos que comportaban contenidos suficientemente precisos y típicos de la cultura occidental, también ella abierta a los estímulos procedentes del resto del mundo.

Y quizá sea lícito detenerse precisamente en el significado de estos conceptos para verificar su extensión y su comprensión, tomando en consideración algunos términos o algunos contenidos expresados en el documento, del modo que se pensaba podía ser el más univoco posible, para verificar su validez y su actualidad en relación con los problemas de la conservación y de la restauración que se debaten en el contexto cultural actual. 


\section{$058-059$ \\ Debate \\ e Investigación}

Fundamentos, fines y

ámbitos de la intervención

en la Carta de Cracovia

\section{PH50 - Octubre 2004}

Los conceptos más generales quedan expresados en el Preámbulo. En éste el porqué de la conservación parece radicar en su relación con el término memoria, en el sentido de connotación y actitud especifica del hombre. La memoria, en efecto, es una característica de todas las culturas y de todos los colectivos, casi como una medida auténtica de la forma a priori del tiempo con la que se interseca estrechamente. En su dimensión antropológica, efectivamente, el tiempo, en su cómo más que en su cuánto ${ }^{1}$, se conecta indisolublemente al sujeto pensante que, al llevar a cabo toda una serie de elecciones o de opciones, conscientes o inconscientes, lo transforma en memoria; ésta a su vez no es otra cosa que lo que, en dialéctica con el olvido, aflora del no ser del tiempo pasado. A través de la memoria el hombre puede tomar conciencia de su ser en el presente, es decir, de su exis$t_{i r}{ }^{2}$. Y la conciencia se encuentra en la raíz de la civilización y de la cultura precisamente como resultado de una elección ${ }^{3}$ deliberada de unos valores que pueden haber sido determinados también en el pasado y que sentimos aún presentes ${ }^{4}$.

El mundo de hoy se encuentra atormentado por el contraste entre unos valores que son inculcados de forma masificada y globalizadora y otros que, por el contrario, emergen de la especificidad de los distintos contextos culturales. Inevitablemente se generan conflictos que tienden, con intenciones opuestas, al aniquilamiento de la especificidad de la pertenencia cultural o a la renuncia a la riqueza típica de toda sensata integración cultural donde las raíces no se dispersan sino que, por el contrario, se fortalecen para formar una cultura más vasta además de más profunda. En el concepto de memoria, en efecto, no están implícitos ni los conceptos de autoexaltación y mutua prepotencia ni el opuesto de la homologación. Por el contrario la sabiduria, y por tanto la civilización, consiste en un continuo ensanchamiento de los ámbitos de la memoria hasta comprender valores que, aun sin haber sido originados por el carácter específico de una cultura determinada que nos pertenece, proceden de ésta, así como de las otras, y han sido reciprocamente adquiridos en el reconocimiento y en el respeto mutuo. En tal sentido el concepto de memoria puede considerarse fundador de una moderna teoría de la conservación, aplicable en un contexto multiétnico formado por diferentes culturas.

La memoria, por otra parte, necesita referencias, cosas que remitan a la memoria. Estas referencias son cada uno de los elementos del patrimonio construido que justamente pueden conservar aún, con pleno derecho, el nombre de monumentos en el sentido de que éstos son portadores de esos valores que son elegidos por la memoria para ser conservados en el conjunto de las conciencias civiles y culturales. Esta elección presupone un reconocimiento que es, a fin de cuentas, una identificación. En el monumento del pasado se elige un valor porque se lo reconoce igual (idéntico) a un valor que vivimos en nuestro presente. De ese modo se crea una identidad entre valores de un colectivo en el tiempo presente y aquellos que se reconocen en el monumento portador de valores del tiempo pasado ${ }^{5}$.
Pero los valores que expresa el presente no son inalterables; es más, el curso del tiempo conduce a una continua transformación de los valores que caracterizan en cada momento los distintos presentes que constituyen la historia. El cambio de los valores del presente conduce, por consiguiente, a una distinta elección de los valores del pasado entre todos aquellos que pueden identificarse en el monumento y del patrimonio en el que ese presente puede identificarse. Los dos términos del proceso de identificación son, pues, frágiles y mutables y el proceso mismo está sometido a continuos cambios en relación con la mutación de los valores a los que la memoria hace referencia. Sin embargo, algo debe encontrarse por debajo de esa mutabilidad del proceso que constituye el sustrato del mismo para que dicho proceso pueda considerarse fundado. Así pues, si los valores cambian, y por consiguiente también las modalidades de las identidades, algo, en la medida de lo posible, debe permanecer inalterado para que las identidades mismas puedan realizarse con referentes seguros e incontrovertibles ${ }^{6}$. Ese algo no puede ser otra cosa que el elemento de permanencia de cada uno de los elementos del patrimonio, eso por lo que dichos elementos son justamente lo que son: esa casa, esa carretera, esa iglesia, ese fragmento de ciudad o ese paisaje.

La determinación de este elemento de permanencia ha dado lugar a disputas y a polémicas acérrimas que han caracterizado una gran parte de la historia de la restauración arquitectónica y de la teoría de la conservación. En efecto, la búsqueda de dicho elemento se ha querido dirigir no al monumento individual sino a un principio abstracto, identificado por algunos en la forma y por otros en la materia y luego, posteriormente, en exigencias de orden estético, expresivo o artístico, funcional, técnico o bien de carácter meramente histórico documental. De ese modo, los defensores de la prioridad de uno de estos principios, que se quería abstraer y deducir de la realidad de la cosa construida y real que es el monumento, llegaban a privar a dicho monumento de las otras connotaciones fundamentales que, en su unidad indisoluble, constituyen la realidad misma y no categorias de conocimiento sustitutorias de ésta. Pero sobre todo, con la sustitución de la realidad por la abstracción se llegó inevitablemente, con grave perjuicio para el patrimonio, a eliminar la connotación sustancial del monumento o de la simple construcción, la más evidente e irreducible a concepto, a principio, a esquema o idea; y ahi reside su existencia como sujeto.

Es bien cierto que cualquier voluntad o intento de conocimiento de la cosa-monumento no puede hacer otra cosa que dirigirse a su carácter fenoménico y revelarse como una objetivación parcial y contingente, aunque funcional a un determinado presente. Pero su principio de permanencia no puede ser encontrado más que en ella misma, en cuanto sujeto irreducible en su mismidad a cualquier otra cosa que no sea él mismo.

Si en el campo filosófico se podria hacer referencia a términos como sustancia, noúmeno, en sí misma, etc., por lo que respec- 
ta a nuestro campo, es decir, en este caso a la teoría de los monumentos, la referencia más espontánea parece ser el término autenticidad. Aunque éste recoge casi todo aquello que, tras una seria investigación, fue precisado en Nara sobre este tema, parece que se puede insistir en el modo en que la etimología primitiva del vocablo puede encontrarse en el término del griego clásico $\alpha v \tau$ ó $\sigma$ en el sentido de esta cosa misma, que luego será retomado por la lengua latina con el vocablo ipse. El $\alpha v \tau$ có $\sigma$, en ese sentido, define la cosa precisamente como ella misma, en su individualidad irreducible y su autenticidad es, en tal caso, no tanto o no sólo la conformidad del monumento a su origen documentado sino el monumento tal y como se nos presenta hoy, con todas las sucesivas estratificaciones que pueden ser también examinadas analíticamente y reconducidas cada una de ellas a su propio origen, valoradas y convertidas en objeto de juicio pero que todas juntas, con otras cosas más, constituyen el monumento en su ser esta cosa.

Todo cuanto está relacionado con el término autenticidad puede así extenderse desde el reconocimiento testimoniado de cuanto concierne al pasado del monumento a cuanto se refiere a los modos de conservación del mismo y, por tanto, a sus modos de utilización y de transmisión al futuro en su integridad sustancial, sin que eso se convierta en algo distinto a él mismo ${ }^{7}$.

Cada acto de conservación se origina en un "responsabilizarse" y se configura también como intervención directa sobre la cosa que se quiere conservar; esta última, a su vez, para conseguir su propio objetivo, precisamente en cuanto tal, en cuanto acción situada en la realidad mundana, no puede dejar de alterar, aunque sea mínimamente, la situación de hecho de sus connotados formales y materiales. Si, por el contrario, se quisiera conservar la materia o la forma, no como connotaciones sino en su carácter absoluto, en cuanto tales y, por tanto, en cuanto abstracciones de la realidad, cualquier acto de conservación se revelaría como una contradicción y no podría ser llevado a cabo. Así pues, el objeto de la conservación debe referirse a la cosa en cuanto tal, al sujeto-monumento entendido en su propia individualidad y la intervención no podrá hacer otra cosa que tomar en consideración la sustancia de la cosa misma en su autenticidad, en el sentido al que se hacia referencia anteriormente.

En tal sentido, el monumento individual, como sustancia, no puede ser reducido a predicado en cuanto que, a la inversa, es un sujeto al que puede referirse a su vez una cantidad indefinible de predicados; eso significa que de las muchísimas cosas que se podrán decir de éste, ninguna, ni siquiera todas juntas, podrán recoger por completo su esencia.

Conservar una entidad semejante presupone, pues, la formulación de un juicio acerca del reconocimiento de la permanencia y, por tanto, de la autenticidad a la que antes se hacía referencia. Sobre el principio de la larga permanencia se ha detenido la filosofía pre-idealista considerándolo un axioma fundamental no sólo en el campo filosófico sino también en el de la física ${ }^{8}$. La arquitectura y también la simple construcción tienen leyes y unas reglas que permiten el reconocimiento del individuo en el conjunto de lo construido, a través del análisis del conjunto de todas las connotaciones que le son propias. Esta identificación se ha producido siempre en el curso de la historia incluso cuando no existía la necesidad de la conservación y los monumentos eran utilizados como motivos para otros proyectos, como utilización de estructuras constructivas, como recuperación de material o bien, de cuando en cuando, también como conservación de la memoria. Ahora la cultura contemporánea ha expresado la necesidad de conservar no sólo fragmentos de memoria en la construcción sino todo el edificio completo en su acepción de autenticidad de la que se hablaba antes. Y si hace sesenta años se demolian altares barrocos en las iglesias medievales en nombre de la famosa unidad estilística, hoy a ningún restaurador o conservador se le ocurriría semejante escandalosa conducta.

Pero resulta imposible también conservar lo construido de manera totalmente acrítica, renunciando a su comprensión, sin poner en pie una actitud que, lejos de ser destructiva, se expresa mediante el análisis y el consiguiente juicio, en los distintos momentos de la historia; y esto significa, por el contrario, el estudio y la acogida de toda esa serie de connotaciones que dan razón de la autenticidad, identificándolas en el monumento mismo y haciéndolas objeto de la intervención de conservación. Se intervendrá pues a través de una serie de elecciones, con la conciencia de que la acción presupone una mutación inevitable pero con la consiguiente responsabilidad de hacer que tal mutación no mancille las partes esenciales propias de la autenticidad del monumento en su integridad.

Está claro que la elección se orientará según unos criterios que resultan ser lo contrario de la arbitrariedad; dicha elección hará referencia, en efecto, a una determinación y ésta, a su vez, a una investigación, según un procedimiento cogitativo-productivo conocido desde la antigüedad", en el sentido de que "toda resolución es una búsqueda, y el último paso del análisis es el primero de la realización"10. Este proceso que lleva del análisis a la realización o a la producción ${ }^{11}$ es un conjunto coordinado de elecciones tal y como puede identificarse en el proceso análisis-indicación de intervención típico del proyecto de restauración, en el que los dos términos están indisolublemente ligados al procedimiento de búsqueda-decisión-elección.

Así pues, es el proyecto, como conjunto de indagación, reflexión y decisión, el instrumento a través del cual se puede cumplir, a distintas escalas, la voluntad de conservación como prolongación en el tiempo de todo el patrimonio construido en su integridad y en su autenticidad. De ello se deriva el hecho de que la conservación viene a identificarse con la finalidad del proyecto de restauración, saliendo del campo del determinismo tecnológicocientífico, en el que había querido confinarla un ansia de mal entendida objetividad, para definirse, en los modos más apropiados 


\section{$060-061$ \\ Debate e Investigación \\ Fundamentos, fines $y$ ámbitos de la intervención en la Carta de Cracovia \\ PH50 - Octubre 2004}

y articulados, en el de la elección motivada y, por tanto, en el proyecto, más adecuado a la naturaleza misma del bien al que pretende dirigirse ${ }^{12}$. Esto no quiere decir en modo alguno que las técnicas no deban desempeñar un papel en el procedimiento metodológico de la conservación; al contrario, sin éstas, la restauración no podría realizarse.

Pero el procedimiento tecnológico no conlleva ningún concepto de elección extraño al suyo propio. La técnica de la conservación de los materiales lapídeos, por ejemplo, tiene como finalidad la de determinar ese procedimiento metodológico en el que se articulan las elecciones técnicas orientadas a su vez al objetivo de la consolidación de esa piedra concreta con la que se ha realizado ese determinado capitel; pero no tiene en cuenta ni la forma del capitel, ni su diseño, ni sus técnicas de ejecución, ni su edad ni sus connotaciones arquitectónicas. Todo ello es competencia de otro ámbito, extraño a esa técnica de consolidación y que comporta otras elecciones que no pertenecen a ese ámbito tecnológico; y así, tanto para éste como para cualquier otro ámbito tecnológico, podemos decir que no existe una técnica de la elección relativa a la intervención en su complejidad y su integridad, a menos que queramos Ilamarla proyecto. La técnica viene así a configurarse como el instrumento indispensable de la restauración, como un momento de elaboración y verificación de las distintas tentativas de elaborar proyectos de conservación relativos al bien específico que se pretende restaurar y que, de otro modo, quedarían estériles o sin respuesta.

Esta reapropiación de la conservación por parte de un ámbito antropológico que querríamos definir como humanista es especialmente significativa en los contenidos del documento de Cracovia. Tras el "Preámbulo", en el capitulo "Fines y Métodos" se insiste una vez más en el concepto de identificación como resultado de un procedimiento cultural que, una y otra vez, se pone de manifiesto en los distintos momentos históricos. El patrimonio arquitectónico, urbanístico y paisajístico es también el resultado de estas sucesivas identificaciones y se presenta bajo la forma de distintos estratos, entendidos como modos diferentes de apropiarse del citado patrimonio y de sus efímeros elementos edificados. Está claro que, contrariamente a lo que sucedia en épocas pasadas, un nuevo concepto de conservación nos induce ahora a expresar dicha identificación con modalidades que respeten la autenticidad y la integridad de la construcción que se pretende restaurar. En ese sentido, deben ser conservados no sólo esos signos, esos volúmenes, esos espacios en los que reconocemos valores semejantes a los nuestros sino también aqueIlos que parecen expresar hoy significados irrelevantes para nosotros, o con los que no nos identificamos. Pero esas partes de los edificios de los espacios urbanos pueden ser portadoras de unos valores que, aunque a nosotros no nos lo parezca, podrían ponerse en evidencia en el futuro. Y es por ello por lo que debemos cuidar también de éstos, incluso dentro de un juicio que, de forma responsable, nos conduce a elegir pequeñas liberaciones o parciales integraciones, bien documentadas, dentro de ese contexto de sensatez del que se hablaba antes. Esta concepción de los fines de la conservación, ya expresada por otra parte en el "Preámbulo", asume los métodos ya precisados en la Carta de Venecia introduciéndolos en el proyecto de restauración. En ese sentido la Carta de Cracovia se detiene en una tipología de intervenciones de conservación más que de instrumentos operativos relativos a términos como liberación, integración, innovación, rehabilitación y otros, entendidos tanto en su valor positivo como negativo. Insiste, además, en los papeles que juegan el mantenimiento y la restauración, con sus diferencias metodológicas y conceptuales, aun dentro de su estrecha y cada vez más deseable complementariedad de relaciones. En tal sentido y en cuan-

\section{Voces}

\section{La conservación y restauración del patrimonio inmueble en España. El caso del Teatro Romano de Sagunto.}

Víctor Pérez Escolano

Catedrático de la ETS de Arquitectura. U. de Sevilla

Desde la reinstauración democrática en 1978, y la sucesiva configuración y actuación de las distintas administraciones públicas de la España de las Autonomias, la arquitectura ha vivido, en todas sus manifestaciones y escalas, una edad de oro, un desarrollo extraordinariamente positivo en su conjunto, en especial en lo que concierne a las obras de iniciativa pública, equipamientos e infraestructuras urbanas y territoriales. Consecuentemente, la consideración del patrimonio inmueble, su conocimiento, pues- ta en valor y las intervenciones habidas para su conservación y restauración, y en su caso su rehabilitación y reintegración, ha alcanzado cotas sin precedentes, tanto cuantitativas como cualitativas, bajo planteamientos y proyectos de muy distinta naturaleza, diversa e incluso antagónica, desencadenándose controversias de gran calado, entre las que el caso del Teatro Romano de Sagunto quizá haya sido la de mayor impacto.

La profunda actualización de las ideas relativas al patrimonio ha conllevado una puesta al dia de la praxis de intervención, al tiempo que se ampliaba hasta todo el siglo XX la consideración patrimonial de las creaciones contemporáneas. En relación con este aspecto, debe recordarse que durante una amplia parte del novecientos se vivió un cierto desprecio, historiográfico y patrimonialista, de las copiosas transformaciones habidas en el siglo XIX, y pareciera que ahora algunos quisieran reeditar ese rechazo hacia las aún mas ingentes contribuciones del siglo XX a nuestro paisaje presente. Reflexionar sobre él, conocerlo y decantar una acción protectora, es 
to al mantenimiento, se insiste en la necesidad de la búsqueda del control así como de las comprobaciones, además de la previsión de la degradación. Estas acciones, en efecto, si bien han sido culturalmente adquiridas y asumidas por los organismos administrativos de los distintos paises, podrian limitar la restauración a un ámbito de intervenciones más restringido del que se necesita en este momento y el mantenimiento mismo podría ser objeto de una programación, evitando de ese modo los gravísimos costes de operaciones esporádicas y desorganizadas.

En cuanto a la restauración se insiste en que sólo puede realizarse mediante un proyecto, en el sentido antes mencionado, y este proyecto debe comprender, sin solución de continuidad, una fase analítica y una fase definitoria para todos y cada uno de los numerosos ámbitos disciplinarios que vienen a confluir a esta disciplina.

Puede parecer una contradicción que la reestructuración aparezca entre las modalidades de intervención que, obviamente, no pertenece en sentido estricto a la restauración ya que presupone una pérdida de autenticidad. Pero se trata de un problema de escalas en el que hay que observar cómo ésta debe ser entendida como algo que se limita a aquellas partes, por ejemplo del patrimonio urbano, donde parece necesario un replanteamiento de los volúmenes constructivos para la readquisición o la precisión de formas urbanas menoscabadas por destrucciones causadas por elementos naturales, bélicos o incluso por la especulación económica. Lógicamente, resulta deseable que tales intervenciones no se lleven a cabo según modelos imitadores de la construcción preexistente sino según criterios en consonancia con la cultura arquitectónica de nuestro tiempo. Así pues, sólo en casos de este tipo, y sobre todo en ámbitos léxicos que no coinciden con la lengua italiana, se puede hablar de reestructuración como de un instrumento de la propia restauración en el sentido de re- miendo de espacios urbanos que han perdido su continuidad morfológica. Es decir, por referencia a una escala inferior a aquella en la que se sitúa precisamente el objeto de la restauración urbana, es decir, casi en el sentido de una integración realizada en un lenguaje contemporáneo.

En un período como el presente, en el que surgen de forma incluso peligrosa cada vez más exigencias de reconstrucción de edificios, parece más que oportuno que el documento insista en la manera en que deben ser evitadas dichas intervenciones así como en el hecho de que las eventuales integraciones de partes amplias de un edificio no pueden llevarse a cabo más que con un lenguaje arquitectónico conforme a la arquitectura contemporánea. También para las reconstrucciones en pareja de edificios destruidos de forma traumática por episodios bélicos o calamidades naturales es deseable que la intervención sea lo más reducida posible y sólo por motivos excepcionales, asumidos y decididos por toda la colectividad.

El problema fundamental de estos últimos puntos parece ser el de la laguna que existe entre las distintas escalas y la intervención de integración que, como consecuencia de ella, debe ser adoptada, siempre que se considere admisible. Y este problema sólo puede ser remitido a decisiones de planes que involucren a toda la colectividad. Parece claro que no se pueden asumir ni prescribir criterios o normas en tal sentido y que, una vez más, se trata de una cuestión de elección en relación con el carácter específico del caso. Al recomendar la máxima atención para evitar todo lo relacionado con la restauración estilística, practicada aún en ciertas áreas europeas, surge al mismo tiempo, de forma espontánea, una consideración acerca de la oportunista e indiscreta asunción de lenguajes de la arquitectura contemporánea en el ámbito de los edificios históricos. Demasiado a menudo, en un cometido en marcha gracias al desarrollo de objetivos concretos como el llevado a cabo internacionalmente por el Docomomo en lo relativo a la arquitectura del movimiento moderno. Es más, se viene procurando desde los medios, que la arquitectura, incluida la de mayor actualidad, goza de inequivocos atributos estéticos y simbólicos que configuran una estima social e institucional similar al proceso habido en otros momentos históricos.

Pero, no nos engañemos, debajo de esa espuma opera un profundo conservadurismo, constatable siempre en el gusto individual, que alcanza a múltiples instancias sociales, incluidos profesionales y universitarios, legisladores y administradores públicos, hasta el particularmente retardatario mundo judicial. En todos ellos, lógicamente, se da la batalla entre corrientes progresistas y tradicionales, incluyendo los arquitectos y otros especialistas del mundo patrimonial. La Ley del Patrimonio Histórico Español de 1985, promovida bajo el primer gobierno socialista, es ilustrativa de esa pugna y su aplicación ulterior ha traido, con sus paradojas, la demostración fehaciente del pulso cultural al que nos referimos. El controvertido punto 2 del artículo 39 de la citada LPHE dice que las actuaciones promovidas por los poderes públicos en el caso de bienes inmuebles, "irán encaminadas a su conservación, consolidación y rehabilitación y evitarán los intentos de reconstrucción", concluyendo el párrafo en una explicita afirmación contraria a las confusiones miméticas. Es sabido que el legislador pretendia con esta redacción poner fin a la prolongada trayectoria de los anticuados "restauradores", reconstructores en lo que se denomina "unidad de estilo". Pero, los efectos perversos de la aplicación de la Ley, sustentada en las demandas nacidas desde esas posiciones reaccionarias, amparadas por administraciones gobernadas por la derecha, derivaron en la sentencia condenatoria del Tribunal Supremo contra la intervención de los arquitectos Grassi y Portaceli en el Teatro Romano de Sagunto, el caso mas paradigmático de esta controversia. Camino por el que han seguido otras sentencias como, por ejemplo, la relativa a la intervención en la Alcazaba de Badajoz, en cuyo ámbito se levantó la Facultad de Bibliotecoeconomía de la Universidad de Extremadura. 


\section{$062-063$ \\ Debate e Investigación}

Fundamentos, fines y ámbitos de la intervención en la Carta de Cracovia

\section{PH50 - Octubre 2004}

efecto, se constata cómo en muchos casos un edificio es asumido solamente como un pretexto o un punto de partida para divagaciones formales que poco o nada tienen que ver con la conservación del bien arquitectónico o ambiental; es más, en muchos casos, este último, aunque rigurosamente conservado sólo en sus aspectos materiales, se encuentra con que desempeña un papel casi de fantasmal fetiche, rodeado de estructuras arquitectónicas que nada tienen que ver con él y que incluso lo ridiculizan al poner en evidencia su carácter completamente extraño; una sensación que es percibida con un claro sentido de malestar por el usuario o por el observador.

Puesto que la reconstrucción estilística es, en efecto, una nueva intervención, los daños que produce son iguales a los de una intervención en un lenguaje arquitectónico que, como se decía antes, no se relacione formal, funcional y técnicamente con el bien mismo. También la reconstrucción en pareja, basada en criterios de fidelidad exacta respecto al texto que ha sido destruido, tomando como referencia el momento de su destrucción, es una intervención "moderna" en cuanto es objeto de una decisión de reconstrucción que hace asumir algunas connotaciones en lugar de otras, como puede suceder con todo lo relacionado con la reconstrucción de la Sala de la Fenice, del Castillo de Berlín o de la Casa del Mercante de Riga o, para volver al pasado, a las reconstrucciones de Varsovia y de Dancica. Sin embargo, parece evidente que estas intervenciones, que sobrepasan totalmente el campo de la restauración, son realizadas solamente tras algunas decisiones que implican, como se decía anteriormente, a las asambleas administrativas y políticas de los distintos niveles, desde el municipal hasta el estatal.

Los instrumentos y las metodologías de la Carta de Venecia, como hemos dicho, se reconocen explícitamente como válidos en la
Carta de Cracovia y, por consiguiente, son asumidos de nuevo hoy por su significado metodológico y operativo. Pero esos instrumentos y esos métodos son recibidos ahora dentro de una dimensión proyectual de la operación de conservación y de la intervención de restauración que aparece subrayada de manera especial. Así pues, se recoge y se explicita la exigencia de que el proyecto incluya todas las fases, desde las indicaciones de los estudios preliminares hasta los análisis, las indicaciones de la intervención, la previsión de la degradación y la programación del mantenimiento. En esa dimensión suya proyectual, compleja y articulada, la restauración adquiere una necesidad de adecuación a la realidad física y antropológica que se explicita de forma diferenciada en los distintos ámbitos y a las distintas escalas de la intervención.

Así, en referencia a esta cuestión, para el patrimonio arqueológico se pone de relieve, en consideración a su vulnerabilidad, el principio de la mínima intervención al que no sólo debe atenerse el restaurador sino el propio arqueólogo en la fase de excavación que, a menudo, puede asumir una característica destructiva. Pero hay que esperar también que la intervención se contextualice en el territorio y en el paisaje siguiendo un plan general, evitando hipertrofias, desequilibrios o desviaciones como esas despreciables formas de homologación debidas a su uso predominantemente turístico.

En cuanto a las indicaciones que se refieren al patrimonio de las construcciones monumentales propiamente dichas, se insiste con fuerza en la necesidad de conservar su integridad, además de su autenticidad, entendida como resultado de todos los testimonios del pasado que están presentes en el edificio. Del mismo modo se subraya la unidad indivisible de superficies, volúmenes, espacios internos y acabados y esto, sobre todo, en oposición a una cierta tendencia al fachadismo que aún persiste en ciertos ambientes, inclu-
En mi opinión, no hay mejor análisis al respecto que el realizado por el Catedrático de Derecho Administrativo de la Universidad Complutense, Santiago Muñoz Machado, en su librito La resurrección de las ruinas (el caso del Teatro Romano de Sagunto) (Civitas, Madrid, 2002). Por encima de las posiciones "de parte" entre las distintas "escuelas" de arquitectos y patrimonialistas, que tan habituales han sido, mas aún sobre ese caso, los argumentos de Muñoz Machado resultan concluyentes: no se puede ejecutar lo sentencia en cuanto a la demolición de lo realizado según el proyecto contemporáneo, pues debe seguirse el criterio establecido de antiguo por el Consejo de Estado francés ("I'ouvrage public mal planté ne se détruit pas"); y lo que se debe es modificar la LPHE para perfeccionarla en pos de alcanzar inequivocamente la obligada sintonia entre el propósito del legislador y su intérprete judicial. Pero, es más, nos remite al fondo de la cuestión cuando afirma: "a la vista de las Sentencias que la han condenado, cualquier espiritu sensible debe preguntarse si tal intervención sobre unas ruinas es tan excepcional, en términos comparados, que merezca ser abominada".
La sensibilidad contemporánea, su reconocimiento y su feliz puesta en práctica, es el verdadera nudo gordiano. Desde la transición democrática, el desarrollo espectacular de la arquitectura española, alcanzó también, como consecuencia de la nueva mirada integral sobre la ciudad histórica y su necesaria rehabilitación, a los proyectos de intervención sobre lo construido, sobre el patrimonio heredado considerado de manera abierta en sus posibilidades de revitalización y reintegración a la vida social. Ha habido de todo en ese caudaloso flujo de actuaciones, y al esfuerzo de puesta al dia de unos le deberá acompañar en otros el reconocimiento de los errores cometidos. Pero esta radical alteración del statu quo patrimonial es irreversible, forma parte de la cultura de nuestro tiempo. Su dificultad reside, mas allá del exigible discernimiento de las cualidades objetivas de la intervención sobre los enclaves monumentales mas relevantes, en la frágil y subjetiva aplicación, creativa y perceptiva, de la sensibilidad contemporánea. 
so culturales, de la arquitectura contemporánea. Es aquí donde surge el tema de la indispensable compatibilidad de la función respecto al organismo que se pretende recuperar. Demasiado a menudo, en efecto, podemos constatar situaciones muy forzadas, debidas a la ausencia de un estudio de compatibilidad, que conducen a acrobacias compositivas y a invenciones de léxico arquitectónico cuanto menos despreocupadas, si no peregrinas o fallidas.

Y una vez más, las recomendaciones relativas al patrimonio artístico, que constituye una unidad con el patrimonio arquitectónico del que forma parte, hacen referencia al concepto de integridad.

También la conservación y la restauración de los elementos decorativos, de las esculturas y de todos esos elementos artísticos o de artesanía presentes en el edificio deben realizarse mediante un proyecto específico unitario, siendo conscientes plenamente de todos los aspectos técnicos y de las implicaciones artísticas y culturales que existen en la obra. Pero se subraya también que el proyecto que se refiere a ellos debe estar necesariamente integrado en el proyecto global de restauración, con toda su complejidad y unidad, del mismo modo que toda decoración de los espacios de un edificio posee unas características precisas que la relacionan con el carácter específico de éste.

La restauración urbana ha logrado definirse como una rama disciplinar perteneciente a la restauración arquitectónica en vista de que los instrumentos del urbanismo, entendido como planificación, no lograban ya dar respuesta a todas las exigencias metodológicas y de contenidos ligadas a la conservación de los centros históricos. Si el concepto de plan resulta imprescindible aún hoy en la dimensión operativa de la intervención, resulta indispensable también que todas las características técnicas de la conservación del patrimonio construido se integren en dicho plan. Pero para que entre el plan y dichas técnicas no se produzca una fisura, un espacio carente de competencias especificas en el que el primero no encuentra instrumentos para realizarse y las segundas no encuentran referencias para su correcta aplicación, es necesario también aquí determinar un ámbito de carácter arquitectónico donde el plan pueda convertirse en proyecto $y$, de ese modo, realizarse a través de las técnicas. En ese sentido la restauración urbana, dentro de su propio contexto de planificación $\mathrm{y}$, por tanto, de su propio ámbito económico y socio-cultural, debe identificar ese conjunto indivisible de edificios y de espacios cubiertos que constituyen áreas unitarias en la homogeneidad y en la continuidad del tejido de la ciudad; a estas áreas deberán referirse los distintos proyectos.

En estos conjuntos, los edificios asumen un significado propio y preciso, tanto en relación a la forma urbana que definen como en relación a la ordenación distributiva de espacios internos que los fundamenta, testimoniando, por otra parte, sus modos de vida como si fueran valores intangibles estrechamente ligados al carácter específico del asentamiento urbano.
La restauración urbana, de este modo, se concreta en el ámbito de lo construido donde los edificios son al mismo tiempo, siguiendo un proceso de interrelaciones continuas, resultados y puntos de partida de los espacios urbanos que definen.

Este concepto de plan, como es lógico, se pone especialmente de relieve también cuando se habla de paisaje. En ese caso se hace referencia a un plan que pueda abarcar al patrimonio, en una dimensión histórico-temporal, como resultado de una "prolongada interacción de distintas sociedades entre el hombre, la naturaleza y el medio ambiente físico". En toda la Carta de Cracovia se considera un elemento fundamental el tiempo en su hacerse historia, pero aquí, de manera especial, está unido a ese "mutar" del paisaje en relación a las indispensables mutaciones determinadas por el desarrollo sostenible, aunque permanezca fielmente apegado al concepto de identidad. Y esto en una concepción de paisaje estrechamente ligada al ambiente construido de las metrópolis y de las ciudades. Es especialmente significativa la observación por la cual "la integración entre la conservación del paisaje cultural, el desarrollo sostenible en las regiones... y las características naturales, exige la comprensión y la conciencia de las relaciones a lo largo del tiempo". En este sentido y bajo esta acepción de una conservación de la autenticidad y de un cambio continuo de las identidades, adquiere una especial importancia el factor dinámico, ligado a la conciencia del transcurrir del tiempo, en el que se fundan y se integran la conservación del paisaje arqueológico y la de los signos más recientes que testimonian el vivir actual del hombre.

Ya se ha hablado en otros puntos sobre la importancia de las técnicas en el ámbito de la conservación y de la restauración. Parece especialmente importante que, junto a los buenos deseos acerca del desarrollo de la investigación científica e interdisciplinar sobre los materiales y sobre las tecnologías, se subraye con fuerza que "la intervención elegida debe respetar el uso [estructural] original y asegurar su compatibilidad con los materiales, las estructuras y los valores arquitectónicos existentes". Y en este sentido la prioridad de la estructura original existente viene a plantearse de forma clara en cualquier intervención de restauración y consolidación. Ésta debe ser continuamente controlada y verificado su comportamiento a lo largo del tiempo así como la posibilidad de eventuales reversibilidades. Finalmente, parece quedar silenciada en el ámbito europeo, y no sólo en las consideraciones de algunos profesionales, la presencia de tesis ambiguas, por no haberse profundizado nunca en ellas, según las cuales la estructura, desde sus cimientos, no habría formado parte de la sustancia arquitectónica; los resultados de estos malentendidos son visibles por doquier en Italia y en el extranjero, en arrogantes estructuras que, con el pretexto de hacer posible el reconocimiento de la intervención, de hecho son apuntalamientos metálicos, tal vez pintados en deslumbrantes colores, azul, rojo o amarillo u otros que, al desvirtuar y absorber la función estática existente, la reducen a un inútil y ridículo oropel. Contra esto la Carta de Cracovia parece ser una explícita y esperada lla- 


\section{$064-065$ \\ Debate \\ e Investigación}

Fundamentos, fines y

ámbitos de la intervención

en la Carta de Cracovia

\section{PH50 - Octubre 2004}

mada al sentido común, finalmente compartido por los estudiosos casi en su totalidad.

Para concluir estas breves notas expuestas hasta el momento, se puede decir que la Carta de Cracovia ha focalizado algunos aspectos de la conservación y de la restauración que, aun estando presentes en el pensamiento de algunos especialistas, aún no habían sido expuestos a la atención de un simposio de autoridades tan amplio, vasto y autorizado. Un simposio que no se ha formado en una institución determinada sino que estaba constituido por expertos de diferentes instituciones que, especialmente en los últimos años, se habian enfrentado a los temas de la conservación: desde la Universidad hasta el ICOMOS, el ICCROM, la UNESCO, Ios ministerios de los bienes culturales y los profesionales más comprometidos.

Una de las líneas de mayor relieve consiste en el hecho de que en este simposio de autoridades el patrimonio no es considerado solamente desde el punto de vista estético o histórico (evitando así toda una serie de malentendidos originados por una cultura de origen idealista), sino en calidad de bien que debe ser adquirido por la comunidad en su conjunto.

Una relevancia especial adquiere, desde este punto de vista, la conservación y la restauración del centro urbano y del paisaje dentro de un plan general de desarrollo sostenible. Dentro de esta realidad es donde se pueden desarrollar las distintas identidades que podrán reconocerse en un concepto del patrimonio cada vez más vasto donde los monumentos desempeñan un papel insustituible en su integridad y su autenticidad. El principio gracias al cual resulta posible este reconocimiento es el opuesto a la homologación que caracteriza una gran parte de la cultura contemporánea y consiste en la memoria, entendida como una auténtica "forma a priori" de cada hombre y gracias a la cual encuentran sentido también los monumentos reconocidos e identificados en el resto de las construcciones, en ámbitos de identidad especifica que aún no nos pertenecen.

En el concepto de memoria el simposio ha reconocido, implícito, el de elección, como ya se decía en su alternancia con el del olvido. La elección es entendida como una operación consciente y capaz de distinguir lo que puede y debe ser conservado como bien y, por tanto, como valor, de lo que no lo es.

Así pues, casi todos los estudiosos han estado de acuerdo en reconocerle a la conservación el valor de finalidad de la restauración y a esta última, además, también un carácter específico de elección que, como se ha dicho anteriormente, se configura en forma de proyecto. En el terreno de los proyectos, las técnicas, entre las que se encuentra la de la conservación, vienen a configurarse como procedimientos indispensables para el mantenimiento a lo largo del tiempo de los materiales de lo construido, pero no como finalidades en sí mismas o como instrumentos únicos de la restauración. Con estas últimas afirmaciones, la cultu- ra de la restauración europea ha querido pasar definitivamente de la materia a una concepción más vasta, y quizá de carácter más humanista: la del proyecto de restauración, entendido como conservación de la obra construida para que pueda formar parte de nuestro presente, de nuestra vida.

${ }^{1}$ M. Heidegger, La concepción del tiempo, Marburgo 1924.

2 “Los dioses eternos están/ siempre llenos de vida; pero incluso en la muerte/ También el hombre puede parecer el mayor bien de la memoria./ Y entonces vive cuanto tiene de más alto", Hölderlin, Himnos, II Reno.

${ }^{3}$ Recogiendo precisamente el término valor en el sentido en que lo afirmaba Cicerón, es decir, como algo que es "selectione dignum", Cicerón, De finibus bonorum et malorum, III, 6, 20.

4 " ¿Qué es lo que ha pasado? Nada más y nada menos que el mundo dentro del cual éstas las cosas-, formando parte de un conjunto de utilizables, eran encontradas como tales y eran usadas por un ser presente-en-el-mundo que las cuidaba. El mundo ya no existe pero lo que de intramundano subsistia en aquel mundo está todavia presente", M. Heidegger, Ser y tiempo, § 73, p. 565, traducción de Pietro Chiodi, Milano, 1970.

${ }^{5}$ Esta dimensión del tiempo como elemento referido al sujeto que lo conjuga en distintas situaciones según una actividad psíquica está bien clara también en el mismo Aristóteles: "Pero si es cierto que en la naturaleza de las cosas sólo el alma, o el intelecto que está en el alma, tienen la capacidad de numerar, resulta imposible la existencia del tiempo sin la existencia del alma", Aristóteles, Física, IV, 223 a 25

6 "Sólo en la sustancia permanente son posibles las relaciones temporales", Kant, Crítica de la razón pura, Analítica trascendental, libro II, capítulo II, sección III, Principio de la permanencia de la sustancia.

"Sólo por medio de la sustancia permanente adquiere la existencia, en las distintas partes de la serie temporal, una cantidad que se llama duración", ibidem.

"El tiempo no puede ser percibido en sí mismo; por ello este permanente es, en los fenómenos, el sustrato de todas las determinaciones temporales", ibidem.

"Así pues, en todos los fenómenos, lo permanente es el objeto mismo, o sea la sustancia (phaenomenon); en cambio, lo que cambia, o puede cambiar, pertenece solamente al modo en que esta o estas sustancias existen y, por consiguiente, a determinaciones de éstas" ibidem.

"El esfuerzo de conservarse es la esencia misma de la cosa", Spinoza, Ética, IV 22. cor.

7 "En la sustancia no hay movimiento si no es accidental ya que no existe ningún ser opuesto a la sustancia", Aristóteles, Física, V (E), 225 b 10

${ }^{8}$ Kant, Crítica de la razón pura.

9 "La elección va unida al razonamiento y al pensamiento", Aristóteles, E. N. 1112 a 15

${ }^{10}$ Ibidem, 112 b 23

11 "La fase cogitativa es la que procede del principio y de la forma; la productiva, en cambio, tiene como punto de partida la conclusión de la fase cogitativa", Metafísica, 1032 b 14-18.

12 "Además, deliberamos más sobre el arte que sobre la ciencia; efectivamente, tenemos más incertidumbres respecto a las primeras", Aristóteles, Ética Nicomachea, 1112 b 7.

Nota

Este texto ha sido traducido del italiano por Rosalia Gómez. 